\title{
Closed reduction internal fixation rates and procedure times for metacarpal fractures treated in a minor surgery area before and after the introduction of a mini C-arm unit
}

\author{
RC Mahabir MD ${ }^{1}, C M$ DeCroff $B_{S c}^{2}, L$ Thurgood $R N^{3}$, AR Harrop MD ${ }^{4}$
}

\begin{abstract}
RC Mahabir, CM DeCroff, L Thurgood, AR Harrop. Closed reduction internal fixation rates and procedure times for metacarpal fractures treated in a minor surgery area before and after the introduction of a mini C-arm unit. Can J Plast Surg 2008;16(3):162-164.
\end{abstract}

BACKGROUND: Mini C-arm units are compact, mobile, fluoroscopic imaging systems designed for real-time imaging of the extremities. They deliver the lowest possible radiation exposure to the patient and physician while minimizing operator effort and inconvenience.

METHODS: A retrospective chart review was undertaken for consecutive metacarpal fractures requiring internal fixation treated in the minor surgery centre before $(n=100)$ and after $(n=100)$ the introduction of the mini C-arm. Open versus closed approach, procedure time and total operating room time were recorded.

RESULTS: Before the introduction of the mini C-arm, the percutaneous rate was $48 \%$ and the average procedure and total operating room times were $55 \mathrm{~min}$ and $102 \mathrm{~min}$, respectively. After mini C-arm implementation, the percutaneous rate increased to $59 \%$ and the average procedure and total times were $36 \mathrm{~min}$ and $78 \mathrm{~min}$, respectively. CONCLUSIONS: The use of a mini C-arm increased the rate of successful closed reduction internal fixation and reduced the procedure time for metacarpal fractures treated in the minor surgery area.

Key Words: Fixation, Hand; Mini C-arm; Operative time; Percutaneous rate; Reduction
Taux de réduction fermée par fixation interne et durées d'intervention pour le traitement de fractures du métacarpe dans un service de petite chirurgie avant et après la mise en place d'un mini-appareil de radioscopie sur arceau («C-arm»)

CONTEXTE : Les mini-appareils de radioscopie sur arceau sont des machines compactes, mobiles, d'imagerie radioscopique, conçues pour produire des images, en temps réel, des extrémités. Ils diminuent le plus possible l'exposition au rayonnement tant du patient que du médecin tout en réduisant au minimum les efforts du manipulateur et les inconvénients. MÉTHODE : Nous avons entrepris un examen rétrospectif de dossiers de patients consécutifs, traités pour des fractures du métacarpe nécessitant une fixation interne dans un centre de petite chirurgie avant $(n=100)$ et après $(n=100)$ la mise en place d'un mini-appareil de radioscopie sur arceau. Ont été notés le type de réduction : ouverte ou fermée, la durée des interventions et le temps total passé en salle d'opération.

RÉSULTATS : Avant la mise en place du mini-appareil de radioscopie sur arceau, le taux d'intervention percutanée s'élevait à $48 \%$, et la durée moyenne des interventions ainsi que le temps total passé en salle d'opération étaient de 55 minutes et de 102 minutes, respectivement. Après la mise en place de l'appareil, le taux d'intervention percutanée a atteint $59 \%$, et la durée moyenne des interventions ainsi que le temps total passé en salle d'opération se sont établis à 36 minutes et à 78 minutes, respectivement. CONCLUSION : L'utilisation du mini-appareil de radioscopie sur arceau a permis d'augmenter le taux de réussite des réductions fermées par fixation interne et de diminuer le temps d'intervention pour le traitement de fractures du métacarpe dans un service de petite chirurgie.
W ith increasing demands being made on hand surgeons, there is a call for convenient, cost-effective and timeeffective means of caring for patients. Mini C-arm units are user-friendly, compact, mobile, fluoroscopic imaging systems designed for real-time imaging of the extremities. Compared with other imaging devices or with full-size $\mathrm{C}$-arms, mini $\mathrm{C}$-arms are typically less expensive to acquire and operate, they expose the staff and patients to less radiation, and minimize operator effort and inconvenience. Developed in the early 1990s, the mini $\mathrm{C}$-arm has an $\mathrm{x}$-ray tube at one end of the $\mathrm{C}$-shaped unit (for which the device is named) and an image intensifier and charge-coupled device camera at the other. The real-time image is sent to a monitor and converted from analogue to digital, allowing computerized processing to be applied to the image during viewing and permitting the use of data networks for image storage and retrieval. One of the most common uses for mini C-arms is the treatment of fractures through both open and closed approaches.

Subsequent to the introduction of a mini C-arm to the minor surgery centre (MSC) in Foothills Medical Centre (Calgary, Alberta), the question arose as to what extent the device impacted patient care. Given the high volume of metacarpal fractures treated at our institution, we decided to review our experience with metacarpal fractures treated before and after the introduction of this technology. The goal of the present study was to examine the efficacy of a mini C-arm at increasing the successful closed reduction internal fixation rate and decreasing procedure time for metacarpal fractures treated in an MSC. The mini C-arm allows for visualization of the fracture fragments and fixation during the procedure, and may increase the probability of successful treatment with closed reduction and internal fixation. Before the introduction of the

\footnotetext{
${ }^{1}$ Division of Plastic Surgery, Department of Surgery, ${ }^{2}$ University of Nevada, School of Medicine, Reno, Nevada, USA; ${ }^{3}$ Department of Minor Surgery, Foothills Medical Centre; ${ }^{4}$ Division of Pediatric Plastic Surgery, University of Calgary and Alberta Children's Hospital, Calgary, Alberta

Correspondence: Dr Raman C Mahabir, clo Division of Plastic Surgery, 2401 South 31st Street, Temple, Texas 76508, USA.

Telephone 254-493-3690, fax 254-724-0315, e-mail rmahabir@swmail.sw.org
} 


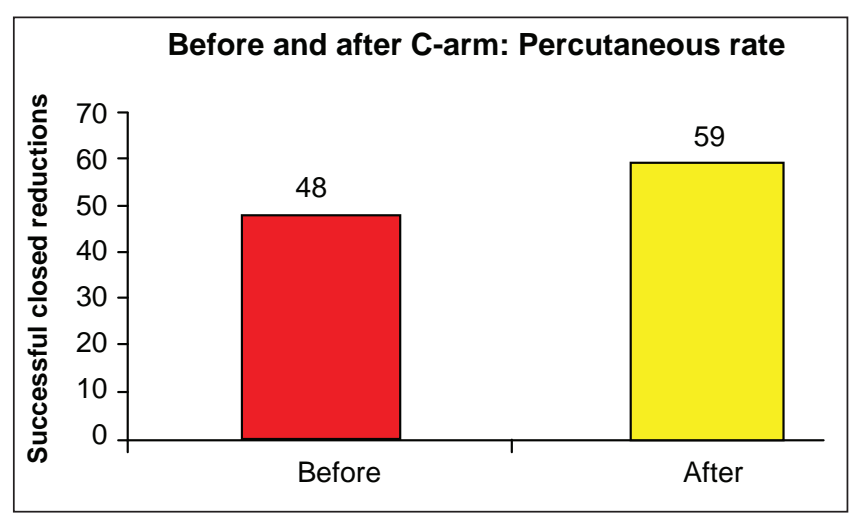

Figure 1) The success rate of closed reduction and internal fixation for metacarpal fractures treated under local anesthetic in a minor surgery centre

device to the MSC, patients were sent to the $\mathrm{x}$-ray department after the procedure. If the reduction or the fixation were found to be inadequate or incorrect (for example: excessive length of screws) then the patient would have to undergo further intervention, costing both time and resources. For this reason, the mini C-arm also represented a potential for time-saving. No studies have been published that address this issue.

\section{METHODS}

A retrospective chart review was undertaken for consecutive metacarpal fractures requiring internal fixation treated in the MSC before $(n=100)$ and after $(n=100)$ the introduction of the mini C-arm. No time period was allotted for a learning curve with the new device. Open versus closed approach, procedure time and total operating room (OR) time were recorded. The procedure time represented the total time under sterile technique. OR time was recorded as the time the patient entered the MSC until the time they left (this included, in addition to procedure time, local anesthesia and splinting). Note that in the 'after introduction of the mini C-arm' group of patients, the mini C-arm was not necessarily used for all patients. Descriptive statistics only were used and results are given as averages rounded to the nearest whole number.

\section{RESULTS}

Before the introduction of the mini C-arm, the percutaneous rate was $48 \%$ and the average procedure and total OR times were $55 \mathrm{~min}$ and $102 \mathrm{~min}$, respectively. After the mini C-arm was introduced, the percutaneous rate increased to $59 \%$ and the average procedure and total times were $36 \mathrm{~min}$ and $78 \mathrm{~min}$, respectively (Figures 1 and 2). Figure 3 shows the average OR times further broken down into open and closed procedures and whether the mini $\mathrm{C}$-arm was used.

\section{DISCUSSION}

The mini C-arm has made a major contribution to surgery of the upper extremity due to its excellent image quality, design features for ease of use, low doses of emitted radiation and the considerable logistical and manpower advantages (1). This is the first study to report an increased success rate with closed reduction with the mini C-arm; it also confirmed the previously reported time saving benefit and the results intuitively make sense.

In the past, closed reduction and internal fixation was performed with only operator palpation to assess accuracy

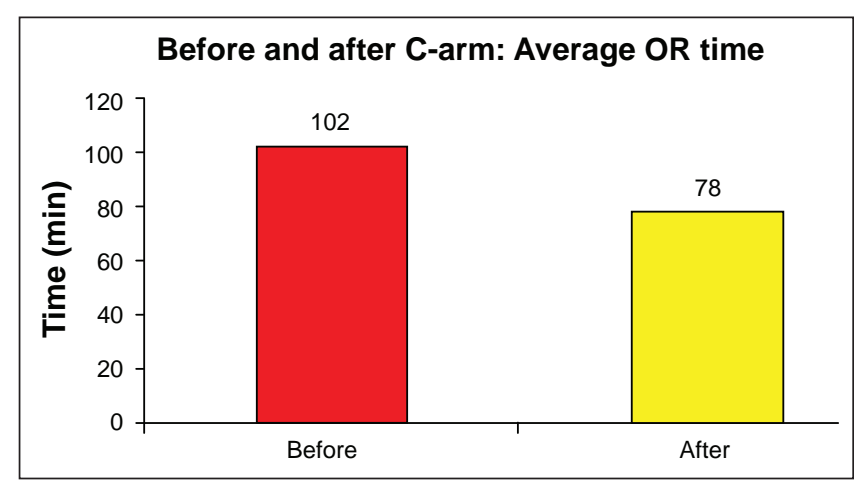

Figure 2) The average operating room (OR) time for reduction and internal fixation of a metacarpal fracture treated under local anesthetic in a minor surgery centre

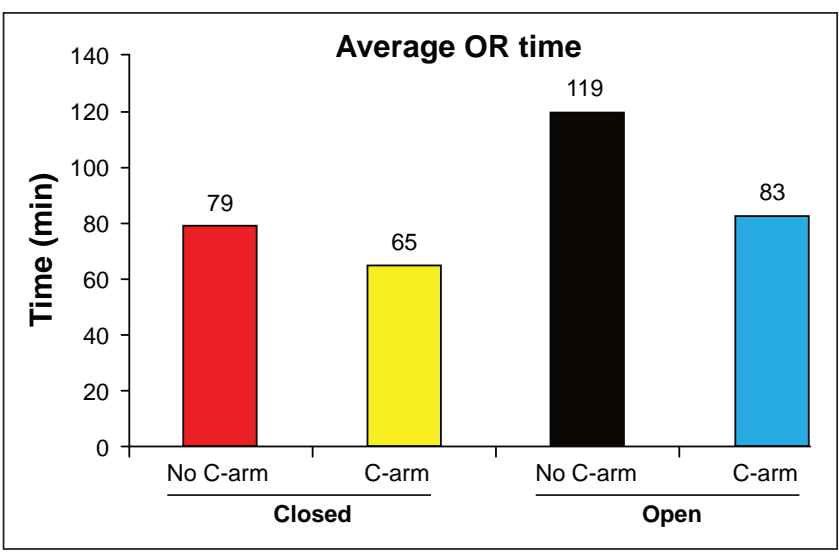

Figure 3) The average operating room (OR) time for reduction and internal fixation of a metacarpal fracture treated under local anesthetic in a minor surgery centre divided into open versus closed and whether the mini C-arm was used

intraoperatively, and patients were sent from the MSC to the radiology department for postreduction films. Occasionally, this meant multiple trips back and forth, increasing procedure time and exposing the patients to the risk of infection. The C-arm provided real-time feedback on reduction and fixation and eliminated the patient transfer to and from the radiology department. In 1999, Wolf and Weiss (2) performed a paired case cohort review of operative times in the main operating room in an attempt to quantify efficiency with and without the use of portable fluoroscopy. While this study had only 30 patients, they were able to demonstrate a time saving of over 30 min.

Use of the C-arm to obtain the desired fixation and to avoid other structures such as joint surfaces or epiphyseal plates is now common. It should be noted that, as with conventional $\mathrm{x}$-rays, there can be distortions of lengths and angles due to object positioning. Because the distance between the source and the image intensifier is short, appreciable magnification of the object can occur depending on the object's distance to the intensifier. This is due to dispersion of the $\mathrm{x}$-ray beam and means that pins can be subject to both magnification and distortion if they are not inserted in the plane of the object (3).

In addition to fixation, mini C-arms offer advantages for foreign body localization. Again, their portability, low emission and ability to take multiple real-time images play an important 
role. A continuous fluoroscopic image can also be taken to facilitate the procedure; however, with a continuous image the radiation exposure is proportional to the duration of the shot. The mini C-arm detects metal, gravel and glass with an accuracy equivalent to that of standard $\mathrm{x}$-rays (4).

The National Council on Radiation Protection sets annual guidelines in the United States for radiation dose limits and recommends that whole-body exposures be less than 5000 mrem per year. The International Commission of Radiological Protection recommends a much lower annual dose of whole-body exposure, limited to 2000 mrem per year (5). Unlike the known effects of high-dose radiation exposure, which can lead to death, the long-term effects from low-dose exposure are much more difficult to assess but may include lifeshortening somatic mutations and heritable mutations (6).

There have been some discrepancies in the literature about the amount of radiation a surgeon is exposed to when using a mini $\mathrm{C}$-arm and whether it necessitates the use of radiationprotective measures. The exposure varies with distance differentials to the beam during any one case. Early studies $(6,7)$ demonstrated substantially lower whole-body exposure rates when comparing the mini C-arm with the standard C-arm and stated that some of the precautions necessary for use of the large $\mathrm{C}$-arm were not needed for the mini $\mathrm{C}$-arm. However, a study by Singer (8) concluded that the actual rate of exposure to a surgeon's hands was 187 times greater than predicted by the manufacturer and recommended that surgeons take precautions against this specific exposure.

One way to significantly reduce exposure is to use the mini $\mathrm{C}$-arm in the horizontal position, with the surgeon standing on the image intensifier side. In this position, the image intensifier provides a cone of safety to vital areas such as the groin, chest and thyroid (6). Some other simple techniques to minimize exposure are shielding (including radiation-resistant surgical gloves), decreasing exposure time, increasing distance, use of laser sighting rather than images for positioning, collimation of the beam, use of the low-dose function on the mini C-arm, use of the last-image-hold feature, use of single-shot instead of real-time fluoroscopy and avoidance of manual power increase $(6,8)$.

A final consideration is financial. When compared with fullsize $\mathrm{C}$-arms or other standard imaging devices, the mini $\mathrm{C}$-arms are more financially favourable not only to purchase, but to operate as well. First, the cost of $\$ 50,000$ to $\$ 70,000$ for the mini $\mathrm{C}$-arm, which is approximately one-half as much as the full-size C-arm, makes the purchase considerably easier for surgical centres to justify (9). Then, the mini C-arm increases efficiency intraoperatively because it delivers images instantaneously and stores them digitally. This eliminates the time and cost of printing films and can alleviate the need for postoperative films by printing copies of the final intraoperative images when needed $(10,11)$. Finally, unlike the standard C-arm, the mini C-arm is operated by the surgeon and does not require a technologist. This has been shown to reduce the demands on the radiology department by up to $15 \%$ (12).
The major limitation of the present study is its lack of analytic statistics. To power this study to detect either an increase in the success rate of closed reduction internal fixation or a reduction in procedure time, a value would have to be selected as significant (ie, is a statistically significant $2 \%$ increase in successful closed reduction internal fixation rate clinically significant or is a statistically significant reduction of $5 \mathrm{~min}$ in procedure time clinically significant?). For this reason, we elected to simply report the average values for 200 consecutive cases. Because we did not allow a period of time for a learning curve, the results should demonstrate the minimum benefit and the actual benefit could be higher as surgeons become more familiar with the technology. Finally, the accrual of these cases took over two years. While there was no staff turnover during that period, there was resident turnover and this may have affected the results.

Ultimately, we determined that the use of a mini C-arm increased the rate of successful closed reduction internal fixation and reduced the procedure time for metacarpal fractures treated in the MSC.

ACKNOWLEDGEMENTS: The authors thank the Division of Plastic Surgery at the Foothills Medical Centre and its surgeons for their support of and participation in this research.

\section{REFERENCES}

1. Sinha S, Evans SJ, Arundell MK, Burke FD. Radiation protection issues with the use of mini $\mathrm{C}$-arm image intensifiers in surgery in the upper limb. Optimisation of practice and the impact of new regulations. J Bone Joint Surg Br 2004;86:333-6.

2. Wolf JM, Weiss AP. Portable mini-fluoroscopy improves operative efficiency in hand surgery. J Hand Surg [Am] 1999;24:182-4.

3. Kummer FJ, Grant AM. Possible errors in pin insertion positions using the C-arm. Bull Hosp Jt Dis 2004;62:67-8.

4. Cohen DM, Garcia CT, Dietrich AM, Hickey RW Jr. Miniature C-arm imaging: An in vitro study of detecting foreign bodies in the emergency department. Pediatr Emerg Care 1997;13:247-9.

5. Hendee WR. History, current status, and trends of radiation protection standards. Med Phys 1993;20:1303-14.

6. Athwal GS, Bueno RA, Wolfe SW. Radiation exposure in hand surgery: mini versus standard C-arm. J Hand Surg [Am] 2005;30:1310-6.

7. Badman BL, Rill L, Butkovich B, Arreola M, Griend RA. Radiation exposure with use of the mini-C-arm for routine orthopaedic imaging procedures. J Bone Joint Surg Am 2005;87:13-7.

8. Singer G. Radiation exposure to the hands from mini C-arm fluoroscopy. J Hand Surg [Am] 2005;30:795-7.

9. Klucas G. C-arm market update. Medical Imaging, December 2000: Kings of the Hill.

<www.medicalimagingmag.com/issues/articles/2000-12_01.asp> (Version current at August 13, 2008).

10. Jones DG, Stoddart J. Radiation use in the orthopaedic theatre: A prospective audit. Aust N Z J Surg.1998;68:782-4.

11. Williams RL, Haddad FS, Clarke AJ. Value of intraoperative image intensifier prints in trauma surgery. Ann R Coll Surg Engl 1996;78:512-4

12. White SP. Effect of introduction of mini C-arm image intensifier in orthopaedic theatre. Ann R Coll Surg Engl 2007;89:268-71. 